Check for updates

Cite this: Chem. Sci., 2019, 10, 10422

๑ All publication charges for this article have been paid for by the Royal Society of Chemistry

Received 30th July 2019

Accepted 28th September 2019

DOI: $10.1039 / \mathrm{c} 9 \mathrm{sc} 03744 \mathrm{f}$

rsc.li/chemical-science

\title{
Programming permanent and transient molecular protection via mechanical stoppering $\dagger$
}

\author{
Miguel A. Soto, (D) a Francesco Lelj (iD ${ }^{b}$ and Mark J. MacLachlan (iD *acd
}

Chemical protection is an essential tool in synthetic chemistry, which involves blocking reactive sites on a molecule through covalent bonds. Physical approaches, such as encapsulation and host-mediated protection, have emerged as interesting alternatives that use steric bulk to inhibit reactivity. Here, we report the protection of a redox-active viologen through its incorporation into mechanically interlocked molecules (MIMs), namely hetero[4]rotaxanes. The viologen was confined inside a host cavity and flanked by two mechanical stoppers, which allowed for permanent and transient protection. Deprotection occurred on-demand via an unstoppering process, triggered by a proton transfer, polarity effect, or a thermal stimulus. We anticipate that permanent and transient mechanical stoppering could be incorporated into devices to function as molecular probes, transport/delivery systems, or stimulicontrolled degradable materials.

\section{Introduction}

Since the introduction of the mechanical bond, numerous mechanically interlocked molecules (MIMs) have been synthesized. [2]Rotaxanes and [2]catenanes are the "simplest" and most documented MIMs, ${ }^{1-5}$ though many other exotic species have been accessed, e.g. hetero $[n]$ rotaxanes, ${ }^{6-9}$ rotacatenanes, ${ }^{10,11}$ knot-capped rotaxanes, ${ }^{12}$ and main-chain poly $[n]$ catenanes. ${ }^{13}$ Currently, research on MIMs involves the synthesis of even more intricate assemblies,$^{14}$ while also focusing on the operation of correlated dynamic processes,${ }^{15}$ and the quest for function, i.e., MIMs performing as catalysts, ${ }^{16}$ sensors, ${ }^{17,18} \mathrm{drug}$ carriers, ${ }^{19}$ molecular electronics, ${ }^{20}$ and machines. ${ }^{21}$

One intriguing approach to achieve function with MIMs is the concept of mechanical protection, ${ }^{22}$ i.e. the shielding of an environment-susceptible substrate by its confinement in the interior of a macrocycle. In this methodology the physical and chemical properties of a substrate (e.g. melting point, solubility, reactivity or degradation) are dramatically altered, so that it no longer behaves as unprotected. ${ }^{23}$ Despite the attractiveness of this approach for synthetic chemistry, only a few MIMs have been prepared with the intention of using mechanical protection. ${ }^{24-36}$ Typically in these examples, the substrate (or

${ }^{a}$ Department of Chemistry, University of British Columbia, 2036 Main Mall, Vancouver, BC, V6T1Z1 Canada. E-mail: mmaclach@chem.ubc.ca

${ }^{b}$ La.M.I. and LaSCAMM INSTM Sezione Basilicata, Dipartimento di Chimica, Università della Basilicata, via dell'Ateneo Lucano 10, Potenza, 85100 Italy

${ }^{c}$ Quantum Matter Institute, University of British Columbia, 2355 East Mall, Vancouver, BC, V6T 1 Z4 Canada

${ }^{d}$ WPI Nano Life Science Institute, Kanazawa University, Kanazawa, 920-1192 Japan

$\dagger$ Electronic supplementary information (ESI) available. See DOI: $10.1039 / \mathrm{c} 9 \mathrm{sc} 03744 \mathrm{f}$ a modified form of it) acts as a recognition site for the protecting macrocycle, then the implementation of an appropriate protocol (e.g. stoppering or clipping) generates a MIM where the macrocycle is secured and provides permanent protection to the substrate. In some specific systems, the protection can be reversed through the degradation of one of the MIM components, which requires a specific input such as an organometallic catalyst $^{22}$ or an enzyme. ${ }^{37}$

Overall, both protection approaches, permanent and transient, are equally relevant. A permanent effect is appropriate to preserve or enhance the properties and function of a substrate during a process, ${ }^{38,39}$ whereas transient protection permits the controlled release of the active substrate once the adverse environment has been evaded. ${ }^{37}$ Here, we present a strategy to protect a molecule both temporarily and permanently by using bespoke stoppering on MIMs. To pursue our concept, we designed two hetero[4]rotaxanes that are depicted in Fig. 1a. These MIMs contain three macrocycles threaded onto a linear species; the central macrocycle functions as a protective unit while the outer macrocycles prevent it from escaping. The outer rings and the thread end-groups act in tandem as mechanical
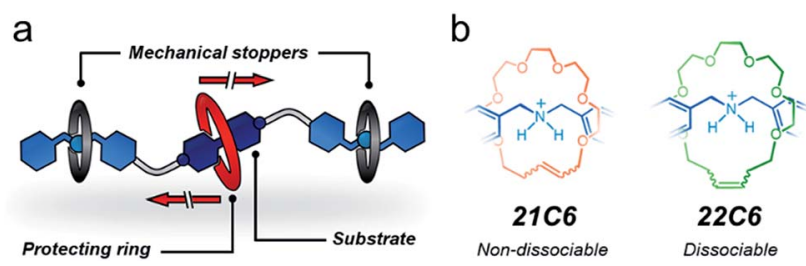

Fig. 1 Schematic representation of (a) a hetero[4]rotaxane structure, and (b) permanently interlocked (left) and metastable (right) rotaxanes constructed from a dibenzylammonium unit and crown ether rings. 
stoppers $^{\mathbf{4 0}}$ to preserve a protected environment around the substrate.

To program both permanent and transient protection, we relied on positioning metastable and permanently interlocked species as mechanical stoppers. Dasgupta and $\mathrm{Wu}$ recently demonstrated that the dibenzylammonium cation can be encircled by [21] and [22]-membered crown ethers (21C6, 22C6) to yield [2] rotaxanes using the clipping method. ${ }^{41}$ The one-atom difference in the macrocyclic structures (21 vs. 22) strongly affects the stability of the MIMs (Fig. 1b). A [2] rotaxane containing 21C6 is permanently interlocked, so it does not disassemble without the cleavage of a covalent bond. Conversely, the 22C6-containing species is isolable but prone to disassemble upon chemical or physical stimulation. Based on these previous observations, we selected the macrocycles 21C6 and 22C6, and the dibenzylammonium motif for the fabrication of two different mechanical stoppers: a dissociable set and a nondissociable counterpart.

We chose the 4,4'-bipyridinium unit, a viologen, as the substrate to protect as these redox-active cations are readily accessible, undergo chemical reduction with a macroscopic readout (color change), and can assemble with several classes of macrocycles, such as pillar[ $n]$ arenes, cucurbit $[n]$ urils and crown ethers. ${ }^{42}$ Considering its tight fit with the viologen derivatives and its relative size and aspect ratio, with respect to $21 \mathrm{C6}$ and $22 \mathrm{C6}$ (see Fig. S1 $\dagger$ ), ${ }^{43}$ we selected the crown ether 1,5-dinaphtho [32]crown-8 (DN32C8) as the protective unit.

\section{Results and discussion}

With the targeted components identified, we synthesized $\left[\mathbf{1} \cdot \mathrm{H}_{2}\right]^{4+}$ (Scheme 1), a linear tetracation composed of a $4,4^{\prime}-$ bipyridinium core that is spaced from two dibenzylammonium moieties by oxybutylene chains. $\left[\mathbf{1} \cdot \mathrm{H}_{2}\right]\left[\mathrm{PF}_{6}\right]_{4}$ was prepared in four steps, in $80 \%$ overall yield, and characterized by HRMS, NMR, and UV-vis spectroscopy (see ESI $\dagger$ ). As with other viologen derivatives, $\left[\mathbf{1} \cdot \mathrm{H}_{2}\right]^{4+}$ undergoes a one-electron reduction when zinc dust is added to a solution of $\left[1 \cdot \mathrm{H}_{2}\right]^{4+} \cdot{ }^{44,45}$ We found that this process is fast ( $<5 \mathrm{~min})$ and leads to a visible color change. Reduction of $\left[\mathbf{1} \cdot \mathrm{H}_{2}\right]^{4+}$ in acetonitrile (pale yellow solution) generates the blue radical cation $\left[\mathbf{1} \cdot \mathrm{H}_{2}\right]^{(3+)} \cdot$ that features structured bands in the UV-vis spectrum, centered at 375 and $575 \mathrm{~nm}$ (Fig. $\mathrm{S} 2 \dagger$ ).

To protect $\left[1 \cdot \mathrm{H}_{2}\right]^{4+}$ from reduction, we first investigated the self-assembly of $\left[\mathbf{1} \cdot \mathrm{H}_{2}\right]^{4+}$ with the protecting ring DN32C8, and tethers $\mathbf{C - 2 1}$ and $\mathbf{C - 2 2}$. The addition of one equiv of DN32C8 to an acetonitrile solution of $\left[\mathbf{1} \cdot \mathrm{H}_{2}\right]\left[\mathrm{PF}_{6}\right]_{4}$ causes a rapid color change from pale yellow to red. This color change is ascribed to the formation of a charge-transfer (CT) complex between the electron-rich DN32C8 and the electron-poor core of $\left[\mathbf{1} \cdot \mathrm{H}_{2}\right]^{4+}$; this complex produces an absorption band at $475 \mathrm{~nm}$ in the UVvis spectrum. Furthermore the ${ }^{1} \mathrm{H}$ NMR spectrum showed an upfield shift for the $\alpha$ and $\beta$ resonances of $\left[\mathbf{1} \cdot \mathrm{H}_{2}\right]^{4+}$ upon mixing with DN32C8 $\left(\Delta \delta_{\alpha}=0.1 \mathrm{ppm}\right.$ and $\left.\Delta \delta_{\beta}=0.3 \mathrm{ppm}\right)$, but the dibenzylammonium signals were unaffected (Fig. S3 $\dagger$ ). These observations suggest that the macrocycle DN32C8 spontaneously threads onto $\left[\mathbf{1} \cdot \mathrm{H}_{2}\right]^{4+}$ and sits on the bipyridinium core to

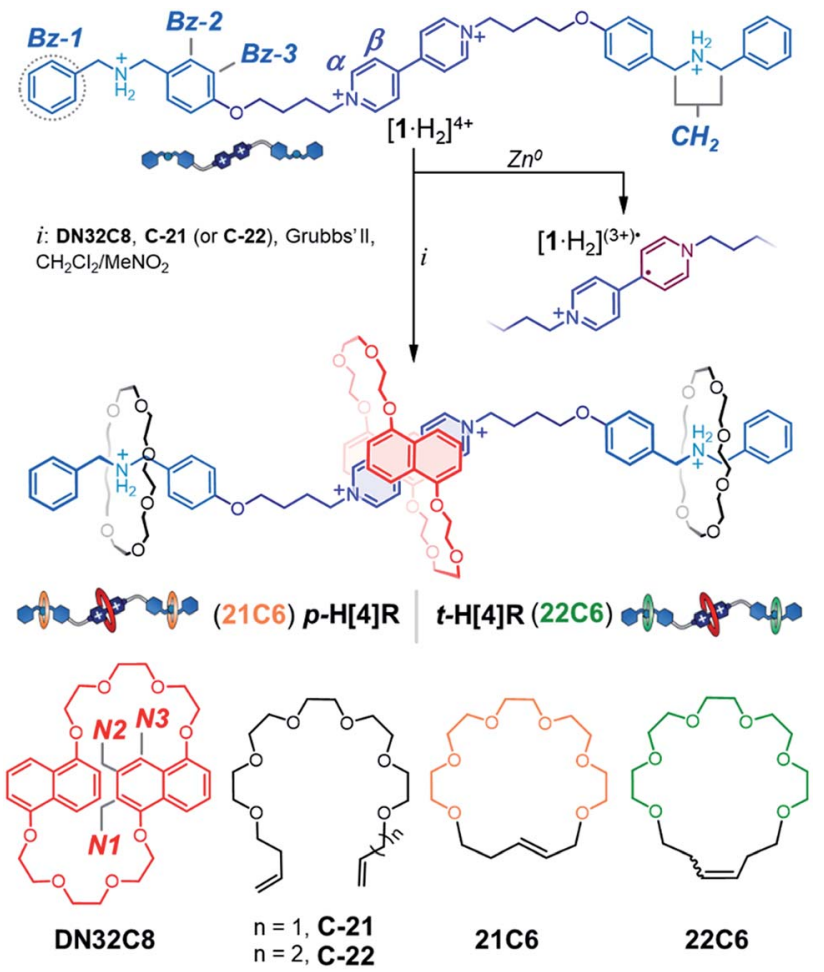

Scheme 1 Syntheses of the two designed hetero[4]rotaxane structures and a thread-like radical cation. Chemical structures and proton assignments for the macrocyclic structures and thread unit are also shown. Note that the radical cation is delocalized.

yield the pseudorotaxane $\left[\mathbf{1} \cdot \mathrm{H}_{2} \subset \mathbf{D N 3 2 C 8}\right]^{4+}\left[\Delta G_{\text {asso }}=-(12.8 \pm\right.$ $0.2) \mathrm{kJ} \mathrm{mol}^{-1}, \mathrm{CD}_{3} \mathrm{CN}, 25^{\circ} \mathrm{C}$, see Table S1. $\dagger$ These spectroscopic data and complex stability resemble those of other reported [2] pseudorotaxane complexes composed of bipyridinium-DN32C8 pairs. $^{46}$

Addition of the precursor C-21 or C-22 to a solution containing $\left[\mathbf{1} \cdot \mathrm{H}_{2} \subset \mathbf{D N 3 2 C 8}\right]^{4+}$ did not interfere with pseudorotaxane formation. Indeed, all components self-sort: DN32C8 encircles the bipyridinium motif, while the glycolic tethers (C21 or C-22) solely wrap the ammonium stations. This was confirmed by the observation of a downfield shift on the ${ }^{+} \mathrm{NH}_{2}$ resonance $\left(\Delta \delta^{+} \mathrm{NH}_{2}=0.2 \mathrm{ppm}\right)$ in the ${ }^{1} \mathrm{H}$ NMR spectrum (Fig. S5 $\dagger$ ). Addition of second-generation Grubbs' catalyst to any of the mixtures containing DN32C8, $\left[\mathbf{1} \cdot \mathrm{H}_{2}\right]^{4+}$, and C-21 (or C-22), followed by heating, led to ring-closure of the glycolic tethers, securing the DN32C8 ring. This reaction yielded the transiently ( $\mathrm{t}$ ) and permanently (p) protected hetero[4]rotaxanes $\mathbf{t}-\mathbf{H}[\mathbf{4}] \mathbf{R}$ and $\mathbf{p}-\mathbf{H}[\mathbf{4}] \mathbf{R}$ in $30 \%$ and $37 \%$ yield, respectively (see ESI $\dagger$ ). ${ }^{47}$ Fig. 2 shows a representative ${ }^{1} \mathrm{H}$ NMR spectrum for one of the isolated species, rotaxane $\mathbf{p}-\mathbf{H}[\mathbf{4}] \mathbf{R}(\mathbf{t}-\mathbf{H}[\mathbf{4}] \mathbf{R}$ data are in Fig. $\mathrm{S}^{\dagger} \dagger$ ).

Using 2D NMR spectroscopy (Fig. S7-S9†), we identified four principal regions in the ${ }^{1} \mathrm{H}$ NMR spectrum: (i) bipyridinium resonances at 8.43/8.40 $\mathrm{ppm}\left(\alpha_{\mathrm{a} / \mathrm{b}}\right)$ and 7.3/7.2 $\mathrm{ppm}\left(\beta_{\mathrm{a} / \mathrm{b}}\right)$; (ii) naphthalene groups at 7.0/6.8 ppm $\left(\mathrm{N} 1_{\mathrm{a} / \mathrm{b}}\right), 6.9 \mathrm{ppm}\left(\mathrm{N} 2 \mathrm{a}_{\mathrm{a}}\right)$, and 6.7/6.5 ppm (N3 $\left.\mathrm{a}_{\mathrm{a} / \mathrm{b}}\right)$; (iii) glycol chains (for the three crown ether rings) at 3.0-4.1 ppm; and (iv) dibenzylammonium signals at 


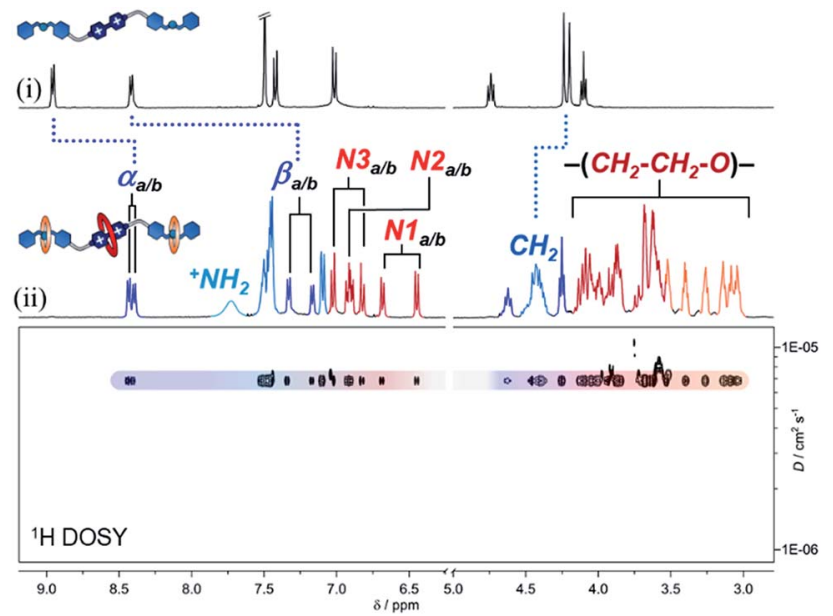

Fig. $2{ }^{1} \mathrm{H}$ NMR spectra $\left(400 \mathrm{MHz}, \mathrm{CD}_{3} \mathrm{CN}\right)$ of (i) compound $\left[1 \cdot \mathrm{H}_{2}\right]$ $\left[\mathrm{PF}_{6}\right]_{4}$ and (ii) hetero[4]rotaxane $\mathrm{p}-\mathrm{H}[4] \mathrm{R} .{ }^{1} \mathrm{H}$ DOSY NMR spectrum is shown in the bottom portion.

$7.7\left({ }^{+} \mathrm{NH}_{2}\right), 7.5-7.1(\mathrm{Bz} 1-3)$ and $4.4 \mathrm{ppm}\left(\mathrm{CH}_{2}\right)$. Integration of the peaks in the ${ }^{1} \mathrm{H}$ NMR data confirmed the stoichiometry of the assembled MIM to be one thread, two 21C6 rings, and one DN32C8 crown ether. This was supported by HRMS, where the parent ion $[\mathbf{1}+\mathbf{D N 3 2 C 8}+(2 \times \mathbf{2 1 C 6})+2 \mathbf{H}]^{4+}$ was detected at $m / z$ $=462.7604$. Furthermore, we proved by diffusion-ordered NMR spectroscopy (DOSY, Fig. 2) that all observed resonances in the ${ }^{1} \mathrm{H}$ data correspond to a single species that diffuses in solution at ca. $6.8 \times 10^{-6} \mathrm{~cm}^{2} \mathrm{~s}^{-1}\left(\mathrm{CD}_{3} \mathrm{CN}, 25{ }^{\circ} \mathrm{C}\right)$, i.e. rotaxane $\mathbf{p}-\mathbf{H}[4] \mathbf{R}$.

The ${ }^{1} \mathrm{H}$ NMR spectrum of $\mathbf{p}-\mathbf{H}[\mathbf{4}] \mathbf{R}$ shows two major differences from that of pure $\left[\mathbf{1} \cdot \mathrm{H}_{2}\right]\left[\mathrm{PF}_{6}\right]_{4}$. First, the bipyridinium resonances $\alpha$ and $\beta$ show an upfield shift $\left(\overline{\Delta \delta}_{\alpha_{\mathrm{a} / \mathrm{b}}}=-0.5 \mathrm{ppm}\right.$ and $\left.\overline{\Delta \delta}_{\beta_{\mathrm{a} / \mathrm{b}}}=-1.2 \mathrm{ppm}\right)$, which is attributed to the confinement of the substrate inside the DN32C8 cavity that leads to shielding from the naphthalene rings. Second, the dibenzylammonium protons $\left({ }^{+} \mathrm{NH}_{2}, \mathrm{Bz}\right.$, and $\left.\mathrm{CH}_{2}\right)$ moved downfield $\left(\Delta \delta^{+} \mathrm{NH}_{2}=0.3 \mathrm{ppm}\right)$ because of hydrogen bonding with the $21 \mathrm{C6}$ rings. The relative position of the [21] and [32]-membered macrocycles, with respect to the thread stations, was supported by NOESY NMR spectroscopy, where through-space couplings were identified for each individual host-guest pair, i.e. dibenzylammonium-21C6 and bipyridinium-DN32C8 (Fig. S8†).

Interestingly, the set of aromatic signals for the bipyridinium-DN32C8 pair splits into two groups ( $a$ and $b$ ) in the ${ }^{1} \mathrm{H}$ NMR spectrum. According to a 2D EXSY experiment (Fig. S9 $\dagger$ ), both $\mathrm{a}$ and $\mathrm{b}$ sets are exchanging at room temperature, indicating the appearance of two isomers that presumably interconvert by an anti/syn isomerization of DN32C8 (Scheme S4 $\dagger$ ). A [3]rotaxane that does not contain this macrocycle features a single set of resonances in the NMR spectrum (see Fig. S10 $\dagger$ ), thus confirming that both isomers of $\mathbf{p}-\mathbf{H}[\mathbf{4}] \mathbf{R}$ emerge as a consequence of the dynamics on DN32C8. ${ }^{48}$

After characterizing the hetero[4]rotaxane molecules, we interrogated them against chemical reduction (Fig. 3a). Separate solutions of $\mathbf{p}-\mathbf{H}[\mathbf{4}] \mathbf{R}$ and $\mathbf{t}-\mathbf{H}[\mathbf{4}] \mathbf{R}$ in $\mathrm{CH}_{3} \mathrm{CN}$ were loaded with zinc dust and stirred under a $\mathrm{N}_{2}$ atmosphere for one day. We did not observe any visible change. UV-vis spectroscopy showed that both solutions preserved their characteristic CT absorption band, at $475 \mathrm{~nm}$, and the radical cation $\left[\mathbf{1} \cdot \mathrm{H}_{2}\right]^{(3+)}$. was not detected (Fig. S11 $\dagger$ ), confirming that DN32C8 effectively protects the bipyridinium substrate in $\mathbf{p}-\mathbf{H}[\mathbf{4}] \mathbf{R}$ and $\mathbf{t}-\mathbf{H}[\mathbf{4}] \mathbf{R}$. The lack of reactivity of the viologen within the rotaxanes is in stark contrast to $\left[\mathbf{1} \cdot \mathrm{H}_{2}\right]^{4+}$, which reacts rapidly $(<5 \mathrm{~min})$ with zinc metal under the same conditions.

Next, we attempted to deprotect both hetero[4]rotaxanes using controlled stimuli. The deprotection step should occur via disassembly of (at least) one of the mechanical stoppers by the disruption of the intercomponent hydrogen bonding. To disable these interactions, we tried three approaches: (i) deprotonation of the ammonium groups; (ii) use of a high polarity solvent; and (iii) application of a thermal stimulus (Fig. 3a). These triggers were first tested on rotaxane $\mathbf{p}-\mathbf{H}[\mathbf{4}] \mathbf{R}$ and then on $\mathbf{t}-\mathbf{H}[\mathbf{4}] \mathbf{R}$.

An $\mathrm{CD}_{3} \mathrm{CN}$ solution of $\mathbf{p}-\mathbf{H}[\mathbf{4}] \mathbf{R}$ was treated with one equiv of base $\left(1 \mathrm{M} \mathrm{NaOH}_{(\mathrm{aq})}\right)$ at room temperature. According to the recorded NMR experiment (Fig. S12 $\dagger$ ), the addition of base did not cause proton transfer; the ${ }^{+} \mathrm{NH}_{2}$ resonance was still observed at $7.7 \mathrm{ppm}$ and other $\mathbf{p}-\mathbf{H}[\mathbf{4}] \mathbf{R}$ signals were unaffected. Furthermore, the molecular ion $[\mathbf{1}+$ DN32C8 + $(2 \times \mathbf{2 1 C 6})+$ $2 \mathrm{H}]^{4+}$ was identified by HRMS $(\mathrm{m} / \mathrm{z}=463.0509)$ while none of the individual components (1, DN32C8 or 21C6) were detected. Thus, deprotonation of $\mathbf{p}-\mathbf{H}[\mathbf{4}] \mathbf{R}$ is inaccessible, probably because of the tight fit between the dibenzylammonium unit and the 21C6 macrocycle. Switching from $\mathrm{CH}_{3} \mathrm{CN}$ to DMSO (a highly competitive solvent) did not produce a different result, and only a change of the anti/syn-DN32C8 isomers ratio was observed, from $1: 1$ in $\mathrm{CD}_{3} \mathrm{CN}$ to $2: 1$ in DMSO- $d_{6}$. Disassembly of $\mathbf{p}-\mathbf{H}[\mathbf{4}] \mathbf{R}$ was not achieved even after several weeks at room temperature in DMSO (see Fig. S14†).

To create a more severe environment, we heated a solution of $\mathbf{p}-\mathbf{H}[4] \mathbf{R}$ in DMSO- $d_{6}$ from 25 to $125{ }^{\circ} \mathrm{C}$ and analyzed it by ${ }^{1} \mathrm{H}$ NMR spectroscopy. Fig. 3b shows the partial aromatic region of the collected spectra (full data in Fig. S15†). Below $\sim 100{ }^{\circ} \mathrm{C}$, both $\mathbf{p}-\mathbf{H}[\mathbf{4}] \mathbf{R}$ isomers were clearly identified; holding $T$ at $100{ }^{\circ} \mathrm{C}$ for one hour did not damage $\mathbf{p}-\mathbf{H}[4] \mathbf{R}$. Elevating the temperature above $115{ }^{\circ} \mathrm{C}$ only caused coalescence of the resonances assigned to the isomers, indicating that their interconversion becomes faster at higher temperatures. We calculated an exchange rate of $110 \mathrm{~s}^{-1}$ at the coalescence temperature (see $\mathrm{ESI} \dagger)$. Furthermore, a $\mathbf{p}-\mathbf{H}[\mathbf{4}] \mathbf{R}$ rotaxane solution prepared in DMSO, and loaded with zinc dust, did not degrade after storage for six months under a $\mathrm{N}_{2}$ atmosphere (Fig. S19†). Together, our observations suggest that $\mathbf{p}-\mathbf{H}[\mathbf{4}] \mathbf{R}$ is permanently stoppered and therefore the bipyridinium substrate is permanently protected. This protection effect is ascribed to (1) the steric shield provided by DN32C8, and (2) the electronic stabilization given by this macrocycle to the viologen substrate; cyclic voltammetry experiments (Fig. S20†) revealed a stabilization of $\sim 13 \mathrm{~kJ} \mathrm{~mol}^{-1}$ with respect to the unprotected species $\left[1 \cdot \mathrm{H}_{2}\right]^{4+}$. Noteworthy, there is only one way to deprotect $\mathbf{p}-\mathbf{H}[\mathbf{4}] \mathbf{R}$ : by breaking covalent bonds. Rotaxane $\mathbf{p}-\mathbf{H}[\mathbf{4}] \mathbf{R}$ was fully disassembled by controlled 
a
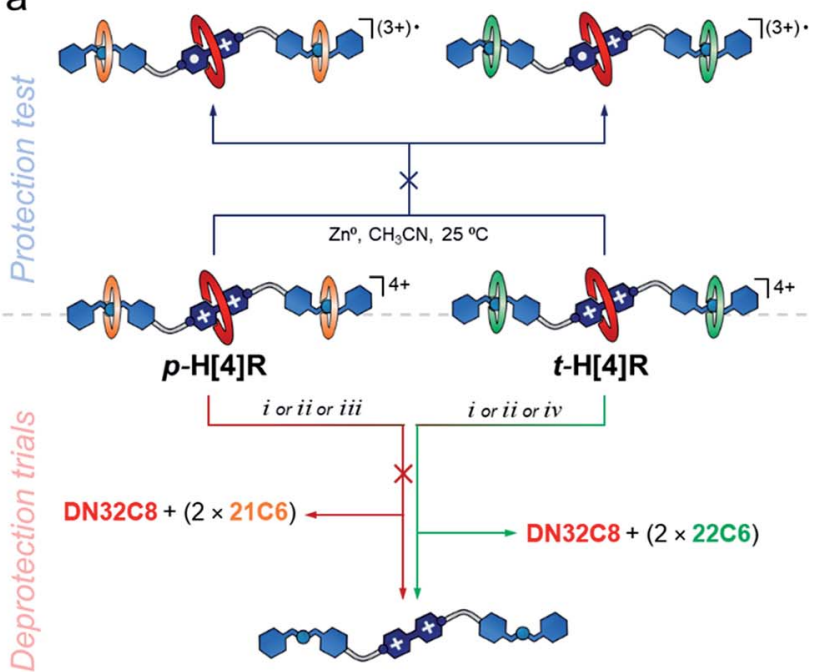

$\left[1 \cdot \mathrm{H}_{2}\right]^{4+}$ or $\mathbf{1}^{2+}$

$i$ : $\mathrm{NaOH}(\mathrm{aq}), \mathrm{CH}_{3} \mathrm{CN}, \mathrm{RT} \mid$ ii: DMSO, RT $\mid$ iii: DMSO, $100-125^{\circ} \mathrm{C} \mid$ iv: DMSO, $90^{\circ} \mathrm{C}$ b
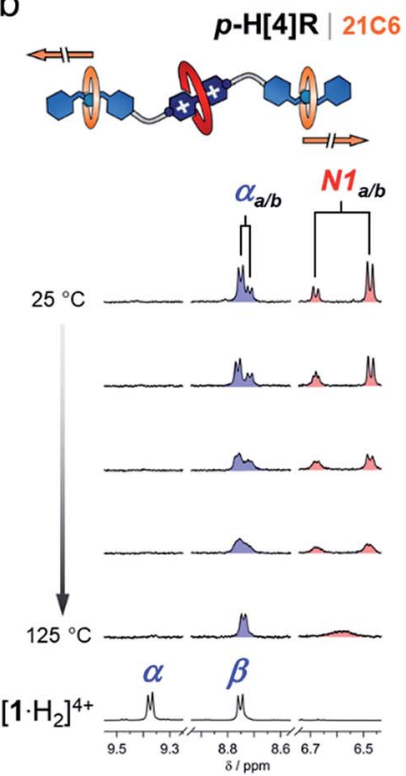
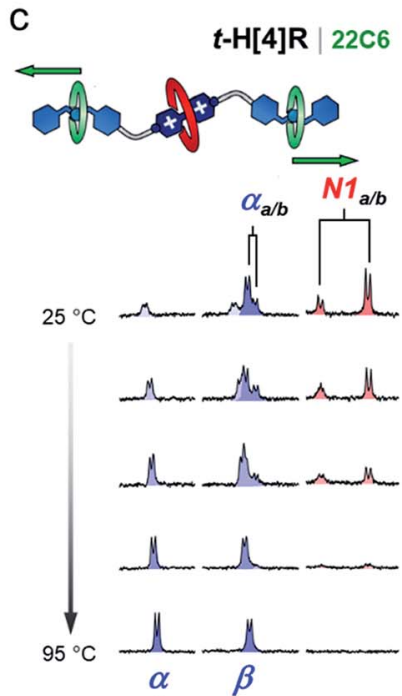

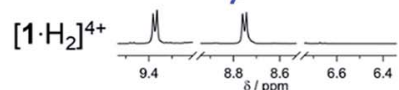

Fig. 3 (a) A scheme showing the tests performed on $\mathrm{p}-\mathrm{H}[4] \mathrm{R}$ and $\mathrm{t}-\mathrm{H}[4] \mathrm{R}$ : deprotection attempt (top) and controlled unstoppering (bottom). (b and c) Partial ${ }^{1} \mathrm{H}$ VT-NMR spectra $(400 \mathrm{MHz}$, DMSO-d ) (b) $\mathrm{p}-\mathrm{H}[4] \mathrm{R}$ and (c) t-H[4]R.

ring-opening of the 21C6 macrocycles, which ultimately released the protecting unit (Fig. S21 $\dagger$ ).

In contrast, we expected that incorporating $22 \mathrm{C6}$ rings into the hetero[4]rotaxane structure would allow transient protection, and breakage of covalent bonds would not be required. We therefore applied the same tested stimuli to $\mathbf{t}-\mathbf{H}$ [4]R. Addition of one equivalent of base $\left(\mathrm{NaOH}_{(\mathrm{aq})}\right)$ to a $\mathrm{CH}_{3} \mathrm{CN}$ solution of $\mathbf{t}-\mathbf{H}[\mathbf{4}] \mathbf{R}$ produced an immediate change in the color of the solution from red to pale yellow, and the characteristic CT band in the UV-vis spectrum disappeared. This indicated that the proton transfer process occurred rapidly and caused two subsequent events: unstoppering followed by the release of the protecting ring. Although the process was too fast $(<1 \mathrm{~min})$ to detect the deprotonated form of $\mathbf{t}-\mathbf{H}[\mathbf{4}] \mathbf{R}$ by ${ }^{1} \mathrm{H}$ NMR spectroscopy, we observed the free thread $\mathbf{1}^{2+}$ and macrocycles 21C6 and DN32C8 in solution by both NMR spectroscopy and HRMS (Fig. S22-S23†).

Dissolving $\mathbf{t}-\mathbf{H}[\mathbf{4}] \mathbf{R}$ in a polar solvent also led to rapid unstoppering. After dissolving t-H[4] $\mathbf{R}$ in DMSO- $d_{6}$ at $25^{\circ} \mathrm{C}$, we observed three new sets of resonances in the ${ }^{1} \mathrm{H}$ NMR spectrum (Fig. 3c) that correspond to the free components 22C6, DN32C8 and $\left[\mathbf{1} \cdot \mathrm{H}_{2}\right]^{4+}$. Integration of the ${ }^{1} \mathrm{H}$ NMR data suggests that $20 \%$ of the complex was rapidly disassembled. Heating the sample up to $95^{\circ} \mathrm{C}$ led to full unstoppering, so that the rotaxane $\mathbf{t}-\mathbf{H}[4] \mathbf{R}$ resonances were no longer evident, while the bipyridinium signals at $9.4(\alpha)$ and $8.7(\beta)$ ppm reached maximum intensity. As well, the free species DN32C8, $\left[\mathbf{1} \cdot \mathrm{H}_{2}\right]^{4+}$ and $22 \mathrm{C6}$, were all found in solution by HRMS (see Fig. S25 $\dagger$ ).

After we proved that $\mathbf{t}-\mathbf{H}[\mathbf{4}] \mathbf{R}$ undergoes controlled unstoppering, we attempted to use this deprotection as a means to control the reactivity of the viologen. A solution of $\mathbf{t}-\mathbf{H}[\mathbf{4}] \mathbf{R}$ in $\mathrm{CH}_{3} \mathrm{CN}$ was loaded with zinc dust, sparged with $\mathrm{N}_{2}$, and left to settle for one hour. Within this period, we did not observe any change, neither macroscopic nor spectroscopic. This implies that the DN32C8 unit stays in place protecting the viologen, an effect that cannot be achieved in systems that are under dynamic assembly/disassembly. ${ }^{45}$ Conversely, upon addition of an alkaline solution $\left(1 \mathrm{M} \mathrm{NaOH}_{(\mathrm{aq})}, 1.0\right.$ equiv.) the mixture rapidly changed color from red to blue. We ascribe this to the unstoppering/deprotection/reduction sequence that gives rise to $\left[\mathbf{1} \cdot \mathrm{H}_{2}\right]^{(3+)} \cdot$ in solution (Fig. S26†) along with residual DN32C8 and $22 \mathrm{C} 6$ units.

Heating $\mathbf{t}-\mathbf{H}[\mathbf{4}] \mathbf{R}$ in DMSO, in the presence of zinc metal, rendered similar results, although the unstoppering followed by

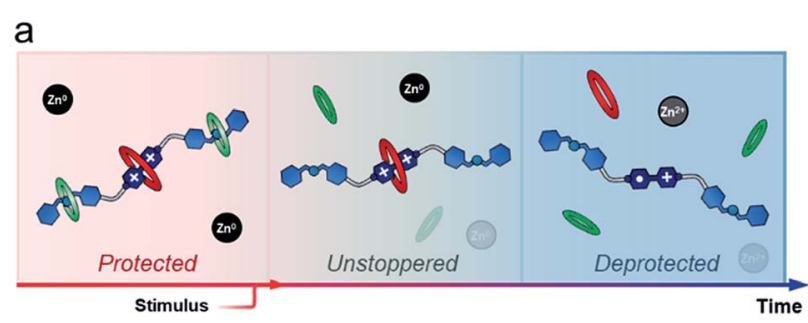

b

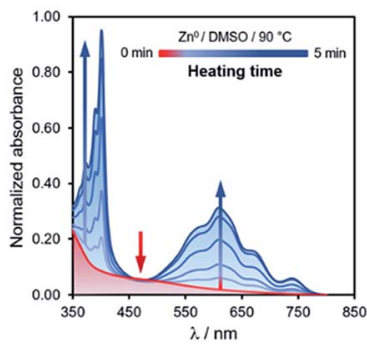

C

Fig. 4 (a) Gradual deprotection/reduction sequence. Experiment conducted on rotaxane $\mathrm{t}-\mathrm{H}[4] \mathrm{R}$ (DMSO, $90^{\circ} \mathrm{C}$ ) and followed at macroscopic scale and by UV-vis spectroscopy (b and c). 
deprotection appeared to be gradual (Fig. 4a). After heating for one minute at $90{ }^{\circ} \mathrm{C}$, we observed a drop in the intensity of the characteristic CT band at $475 \mathrm{~nm}$, and two additional bands assigned to $\left[\mathbf{1} \cdot \mathrm{H}_{2}\right]^{(3+) \cdot}(375$ and $575 \mathrm{~nm})$ were present (Fig. $\left.4 \mathrm{~b}\right)$. Continuous heating at the same temperature produced a concomitant increase of these bands. Interestingly, the deprotection/reduction process was detected at the macroscopic scale. The pale red solution that contained $\mathbf{t}-\mathbf{H}[\mathbf{4}] \mathbf{R}$ gradually transformed into a blue mixture in $\mathrm{ca}$. five minutes at $90{ }^{\circ} \mathrm{C}$ (Fig. 4c), due to the presence of $\left[1 \cdot \mathrm{H}_{2}\right]^{(3+)} \cdot$, i.e. once the unstoppering process was completed.

\section{Conclusions}

In summary, we have synthesized two hetero[4]rotaxane MIMs that resist chemical reduction. Both molecules bear two key components that, in synergy, make protection viable: (1) a central ring that offers steric bulk and stabilizes the sensitive substrate, and (2) a couple of outer macrocycles that prevent the protecting unit from escaping, i.e. the mechanical stoppers.

By selecting between two stoppers, comprising [21] or [22]membered rings, we programmed permanent and transient protection on $\mathbf{p}-\mathbf{H}[\mathbf{4}] \mathbf{R}$ and $\mathbf{t}-\mathbf{H}[\mathbf{4}] \mathbf{R}$, respectively. $\mathbf{p}-\mathbf{H}[\mathbf{4}] \mathbf{R}$ does not disassemble even when exposed to severe environments, whereas $\mathbf{t}-\mathbf{H}[\mathbf{4}] \mathbf{R}$ dissociates to leave the sensitive substrate exposed, on demand. We consider that mechanical stoppering, as a general concept, could be valuable for the design of, e.g., other protected MIMs bearing relevant substrates, delivery systems, and stimuli-controlled degradable materials.

\section{Conflicts of interest}

There are no conflicts to declare.

\section{Acknowledgements}

MAS thanks CONACYT for a postdoctoral fellowship. MJM thanks NSERC for Discovery and CREATE grants. The input provided by Dr Charlotte Boott during the preparation of this manuscript is also acknowledged.

\section{References}

1 H. W. Gibson, M. C. Bheda and P. T. Engen, Prog. Polym. Sci., 1994, 19, 843-945.

2 C. Dietrich-Buchecker, C. M. Jimenez-Molero, V. Sartor and J. P. Sauvage, Pure Appl. Chem., 2003, 75, 1383-1393.

3 M. J. Langton and P. D. Beer, Acc. Chem. Res., 2014, 47, 19351949.

4 E. M. G. Jamieson, F. Modicom and S. M. Goldup, Chem. Soc. Rev., 2018, 47, 5266-5311.

5 X.-Q. Wang, W.-J. Li, W. Wang and H.-B. Yang, Chem. Commun., 2018, 54, 13303-13318.

6 W. Jiang, H. D. F. Winkler and C. A. Schalley, J. Am. Chem. Soc., 2008, 130, 13852-13853.

7 Z.-J. Zhang, H.-Y. Zhang, H. Wang and Y. Liu, Angew. Chem., Int. Ed., 2011, 50, 10834-10838.
8 C. Ke, R. A. Smaldone, T. Kikuchi, H. Li, A. P. Davis and J. F. Stoddart, Angew. Chem., Int. Ed., 2013, 52, 381-387.

9 S.-J. Rao, Q. Zhang, J. Mei, X.-H. Ye, C. Gao, Q.-C. Wang, D.-H. Qu and H. Tian, Chem. Sci., 2017, 8, 6777-6783.

10 G. Barin, A. Coskun, D. C. Friedman, M. A. Olson, M. T. Colvin, R. Carmielli, S. K. Dey, O. A. Bozdemir, M. R. Wasielewski and J. F. Stoddart, Chem.-Eur. J., 2011, 17, 213-222.

11 R. Hayashi, P. Slavík, Y. Mutoh, T. Kasama and S. Saito, J. Org. Chem., 2016, 81, 1175-1184.

12 D. A. Leigh, L. Pirvu, F. Schaufelberger, D. J. Tetlow and L. Zhang, Angew. Chem., Int. Ed., 2018, 57, 10484-10488.

13 Q. Wu, P. M. Rauscher, X. Lang, R. J. Wojtecki, J. J. de Pablo, M. J. A. Hore and S. J. Rowan, Science, 2017, 358, 1434-1439.

14 M. T. Nguyen, D. P. Ferris, C. Pezzato, Y. Wang and J. F. Stoddart, Chem, 2018, 4, 2329-2344.

15 K. Zhu, G. Baggi and S. J. Loeb, Nat. Chem., 2018, 10, 625630.

16 D. A. Leigh, V. Marcos and M. R. Wilson, ACS Catal., 2014, 4, 4490-4497.

17 B. R. Mullaney, A. L. Thompson and P. D. Beer, Angew. Chem., Int. Ed., 2014, 53, 11458-11462.

18 M. Denis, J. Pancholi, K. Jobe, M. Watkinson and S. M. Goldup, Angew. Chem., Int. Ed., 2018, 57, 5310-5314.

19 R. Barat, T. Legigan, I. Tranoy-Opalinski, B. Renoux, E. Péraudeau, J. Clarhaut, P. Poinot, A. E. Fernandes, V. Aucagne, D. A. Leigh and S. Papot, Chem. Sci., 2015, 6, 2608-2613.

20 A. Coskun, J. M. Spruell, G. Barin, W. R. Dichtel, A. H. Flood, Y. Y. Botros and J. F. Stoddart, Chem. Soc. Rev., 2012, 41, 4827-4859.

21 G. De Bo, M. A. Y. Gall, S. Kuschel, J. De Winter, P. Gerbaux and D. A. Leigh, Nat. Nanotechnol., 2018, 13, 381-385.

22 K. Zhu, G. Baggi, V. N. Vukotic and S. J. Loeb, Chem. Sci., 2017, 8, 3898-3904.

23 E. A. Neal and S. M. Goldup, Chem. Commun., 2014, 50, 51285142.

24 A. H. Parham, B. Windisch and F. Vögtle, Eur. J. Org. Chem., 1999, 1999, 1233-1238.

25 J. E. H. Buston, J. R. Young and H. L. Anderson, Chem. Commun., 2000, 905-906.

26 M. Franz, J. A. Januszewski, D. Wendinger, C. Neiss, L. D. Movsisyan, F. Hampel, H. L. Anderson, A. Görling and R. R. Tykwinski, Angew. Chem., Int. Ed., 2015, 54, 6645-6649.

27 L. D. Movsisyan, M. Franz, F. Hampel, A. L. Thompson, R. R. Tykwinski and H. L. Anderson, J. Am. Chem. Soc., 2016, 138, 1366-1376.

28 M. Gauthier and F. Coutrot, Eur. J. Org. Chem., 2019, 21, 3391-3395.

29 Y. Akae, Y. Koyama, S. Kuwata and T. Takata, Chem.-Eur. J., 2014, 20, 17132-17136.

30 R. Eelkema, K. Maeda, B. Odell and H. L. Anderson, J. Am. Chem. Soc., 2007, 129, 12384-12385.

31 A. Mateo-Alonso, P. Brough and M. Prato, Chem. Commun., 2007, 1412-1414. 
32 J. J. Gassensmith, J. M. Baumes and B. D. Smith, Chem. Commun., 2009, 6329-6338.

33 D. M. D'Souza, D. A. Leigh, L. Mottier, K. M. Mullen, F. Paolucci, S. J. Teat and S. Zhang, J. Am. Chem. Soc., 2010, 132, 9465-9470.

34 K. Sugiyasu, Y. Honsho, R. M. Harrison, A. Sato, T. Yasuda, S. Seki and M. Takeuchi, J. Am. Chem. Soc., 2010, 132, 14754-14756.

35 K. Nakazono and T. Takata, Chem.-Eur. J., 2010, 16, 1378313794.

36 C. B. Caputo, K. Zhu, V. N. Vukotic, S. J. Loeb and D. W. Stephan, Angew. Chem., Int. Ed., 2013, 52, 960-963.

37 A. Fernandes, A. Viterisi, F. Coutrot, S. Potok, D. A. Leigh, V. Aucagne and S. Papot, Angew. Chem., Int. Ed., 2009, 48, 6443-6447.

38 E. Arunkumar, C. C. Forbes, B. C. Noll and B. D. Smith, J. Am. Chem. Soc., 2005, 127, 3288-3289.

39 M. R. Craig, M. G. Hutchings, T. D. W. Claridge and H. L. Anderson, Angew. Chem., Int. Ed., 2001, 40, 1071-1074.

40 M. A. Soto and M. J. MacLachlan, Org. Lett., 2019, 21, 17441748.
41 S. Dasgupta and J. Wu, Chem. Sci., 2012, 3, 425-432.

42 Z. Liu, S. K. M. Nalluri and J. F. Stoddart, Chem. Soc. Rev., 2017, 46, 2459-2478.

43 I. R. Fernando, Y. Mo and G. Mezei, CrystEngComm, 2014, 16, 7320-7333.

44 T. Endo, K. Ageishi and M. Okawara, J. Org. Chem., 1986, 51, 4309-4310.

45 X. Chi, M. Xue, Y. Yao and F. Huang, Org. Lett., 2013, 15, 4722-4725.

46 I. R. Fernando, S. G. Bairu, G. Ramakrishna and G. Mezei, New J. Chem., 2010, 34, 2097-2100.

47 For C-22, ring-closing metathesis (RCM) yielded a mixture of cis/trans-22C6 macrocycles within the assembled MIM $\mathbf{t}-\mathbf{H}[\mathbf{4}] \mathbf{R}$ (evidenced by ${ }^{1} \mathrm{H}$ NMR spectroscopy). In contrast, RCM of C-21 produced only one isomer (trans-21C6), which correlates well with previous reports that involved 21C6, 22C6 and the dibenzylammonium motif (see ref. 41). 48 L. Chen, H.-Y. Zhang and Y. Liu, J. Org. Chem., 2012, 77, 9766-9773. 